\title{
Novel Acetylated Linear Periplasmic Glucans Isolated from Pseudomonas syringae
}

\author{
Eunae Cho and Seunho Jung \\ Department of Bioscience and Biotechnology, Biokfolectilar Informatics Center, Konkuk Lniversity, Seoul 143-701, Korea \\ ${ }^{*}$ E-mail: shjungiákonkukackr \\ Recerved July 10, 2009, Accepted August 6, 2009
}

Key Words: Acetylated glıcans. Linear periplasmic glucans. Stnuctural analysis. Psetudomonas șringae

Periplasmic glucans, which exist in periplasmic space of many gram negative bacteria. are biologically important molecules in osmoregulation or pathogenesis. ${ }^{*}$ In fact, mutants unable to synthesize the periplasmic glucans are impaired for growth in low osmotic condition or virulence. ${ }^{2.3}$ These glucans also have biotechnological applications such as chiral additives. ${ }^{4}$ solubility enhancers. ${ }^{5}$ and catalysts. ${ }^{6}$ Those applications of glucans are based on the structure having a complexation property with other compounds containing hydrophobic molecules. "Their structures vary according to the glycosidic linkages. Degree of polymerization (DP), and the cyclic or non-cyclic forms. ${ }^{1}$ Since there has been structural analy sis on various glucans. ${ }^{3.14}$ functional studies depending on structural variation have been expected. Herein. we report structural analysis of newly found periplasmic glucans isolated from Pseudomonas suringae.

P. sringae produces linear structured periplasmic glucans which have $\beta-1,2$ polyglucose chain branched with $\beta-1.6$ linkage. together with Escherichia coll. ${ }^{10}$ Enwinia chrisanthemi." and Psetadomonas aertiginosa. ${ }^{12}$ The periplasmic glucans of $E$. coli were firstly discovered in $1973{ }^{13}$ Since the discovery. many studies on the components in periplasmic spaces of gram negative bacteria have been reported where $P$. svingae produced periplasmic glucans which have similar stnictures to those of $E$. coli. The molecules can also be substituted by non-glucose residues originating from intermediary metabolisms such as acetyl. succinyl and methylmalonyl or the membrane phospholipids such as phosphoglycerol. phosphocholine. and phosphoethanolamine. 'For the acetyl. succinyl and methylmalonyl substituents. acyl-coenzy'mes A is suspected to be the donor. Since the function of substituents in periplasmic glucans is not clear the phy siological role of those is needed to be studied.

It has been reported so far that periplasmic glucans of $E$. $c o l i$ have phosphoglycerol. phosphoethanolamine and succinyl substituents, while E. chrrsanthemi produce succinyl and acetylated periplasmic glıcans. ${ }^{11}$ It also has been known that succinyl subsituents exist in periplasmic glucans of $P$. aeruginosa. ${ }^{\text {l2 }}$ Recently, we have reported succinylated and large sized periplasmic glucans isolated from $P$. syringae in low osmolarity (LO) media. ${ }^{1+}$ In this study. we describe for the first time that $P$. syringae produces one or two acetylated linear periplasmic glucans in high osmolarity (HO) media.

$P$. syringae which is a plant pathogen was grown in $\mathrm{HO}$ media and the glucans were isolated and purified through chromatographic technigues from the cell extract. After anion exchange chromatography through the DEAE column. neutral and anionic glucans were separated and analyzed, respectively. The mass spectrum of the left side shown in Figure la represents neutral linear glucans. and there are 20 potassium and sodium-cationized molecular ions ([unsubstituted linear periplasmic glucans $+\mathrm{K}^{+}$] and [unsubstituted linear periplasmic glucans $\left.+\mathrm{Na}^{+}\right]$). The potassium adduct ions at 867 . $1029,11911353,1515,1677,1839,2001,2163,2326,2488$. 2650, 2812, 2974, 3136, 3298, 3460, 3622. and 3784 are identical to those of unsubstituted linear glucans that contain 5 to 24 glucose residues, together with sodium adduct ions with $m / z$ reduced by 16 below the masses of the corresponding potassium adduct ions.

Peaks at $m / z 1072.1233,1395,1557,1719,1881,2043$, $2205,2367.2530 .2692,2854.3017 .3178,3341.3503$ and 3664 that also correspond to one acetylated DP 6-22 glucans were newly detected with half of the intensity of unsubstituted glucans. Smaller peaks at $m / z \quad 1275,1437,1599,1761,1923$. $2085,2248.2410 .2572,2734$ and 2895 indicate the presence of two acetylated DP 7-17 glucans. An upper enlarged spectrum between $m / z 1450$ and 1800 clearly shows the presence of one or two acetylated glucans with the respective mass difference of $42 .^{193}$ This result indicates that one or two acetylated glucans as a neutral form are synthesized fron $P$. stringae cultured in $\mathrm{HO}$ media.

Compared to Figure la, Figure lb shows a $\mathrm{m} / \mathrm{z}$ shift of 100 and it represents anionic glucans with one succinyl moiety. Their peaks which are $m / z 1291$ 1453. 1615. 1777. 1939. 2101 . $2263,2426,2588$, and 2750 are assigned to potassium adducts. Sodium adducts with $\mathrm{m} / \mathrm{z}$ reduced by 16 are also present and the DP range is $7 \cdot 16$. In the enlarged mass spectrun shown in the right side of Figure lb. two other mass differences of 42 are shown. This fact indicates that these anionic glucans have complexed forms composed of one succinylated glucans with an addition of one or two acetyl residues. The linear nature of these glucans was confimed by the lydrated nolecular weight ( $m / z 18$ added molecular weight) compared with the crclic form.

Additionally, we could detect the presence of reducing glucoses by doublets near 5.4 and 4.7 ppm in proton peaks of ${ }^{3} \mathrm{H}^{1 / 3} \mathrm{C}$-heteronuclear single quantum correlation (HSQC) spectrum (Figure 2a). ${ }^{15}$ A cross peak at 5.4 and 91.8 ppm is indicative of $\alpha$-anomeric ${ }^{1} \mathrm{H}-{ }^{13} \mathrm{C}$ correlation of reducing glucose and a cross peak at 4.7 and 94.9 ppm represents $\beta$ anomeric ${ }^{1} \mathrm{H}-{ }^{13} \mathrm{C}$ correlation of reducing glucose. Previous study on the unsubstituted periplasmic glucans of $P$. svringae that used glycosidic linkage analysis was reported to be highly 

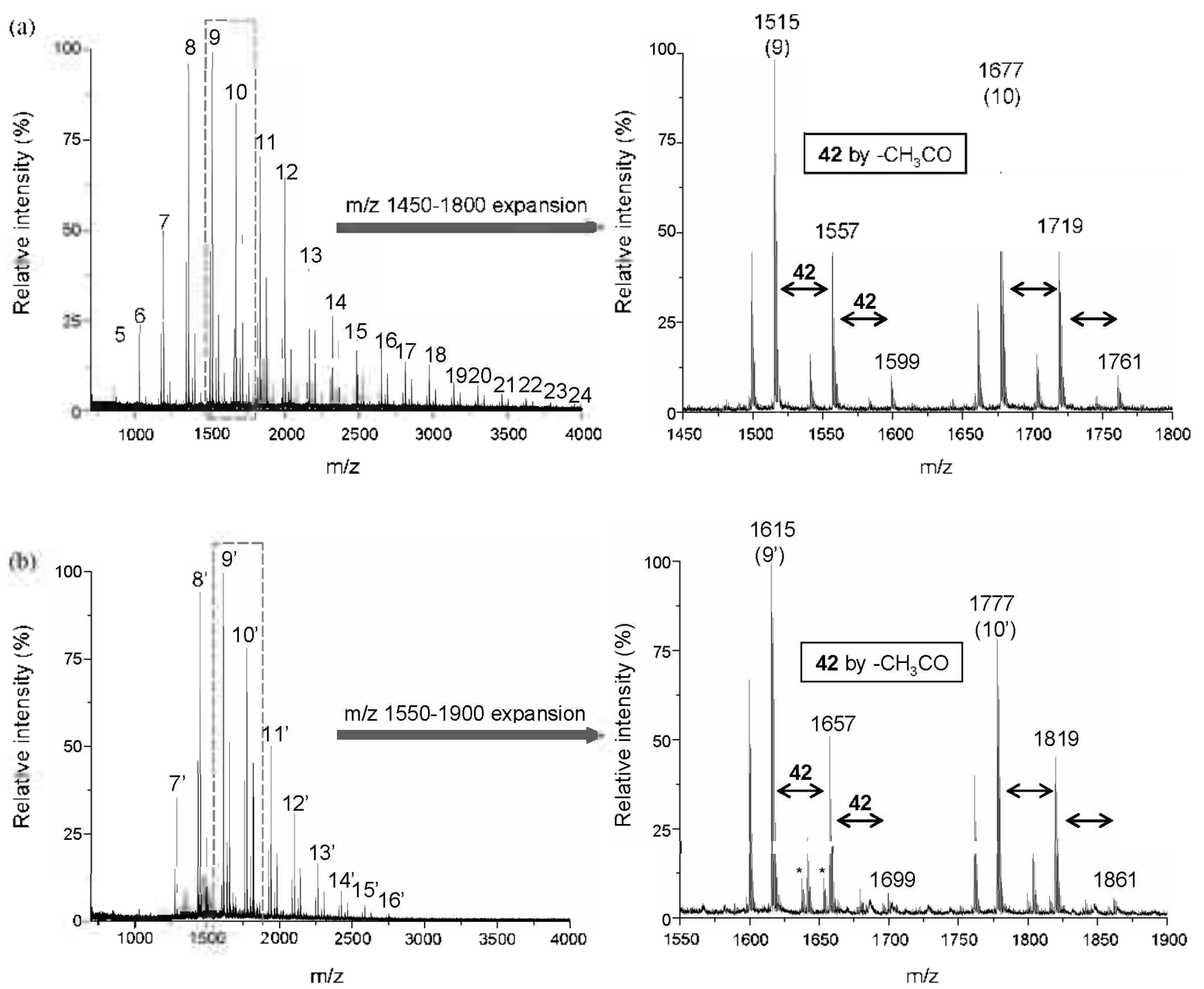

Figun 1. MALIDI-TOI: MS specira ol neutral (a) and anionic glucans (b) isolated lrom $P$ swingae pv. syringale. Number $5-24$ in (a) and number $7^{\circ}-16^{\circ}$ in (b) mean DP ol neutral and anionic glucans, respectively. Finlaroed spectra of $\mathrm{m} / \mathrm{z} 1450-18001$ and $1550-1900$ are shown in the right side of Figure la and b, respectively: * : impurity:

$\beta-1.6$ branched $\beta-1.2$ glucans. ${ }^{\gamma}$ In this report. the presence of $\beta-1.6$ linkages is shown in Figure 2a. C-6 peaks of $\beta$ - 1.6 linkages are assigned near $69.0 \mathrm{ppm}$ and correlated with proton peaks near 4.2 ppin. Two weakly observed doublets ranging from +.3 to $+.5 \mathrm{ppm}$ in the partial ' $\mathrm{H}$-NMR spectrum as shown in Figure $2 b$ are altributed to $\mathrm{H}-6$ and $\mathrm{H}-\mathrm{\sigma}^{\circ}$ of glucose residues having an acetate linked at $\mathrm{C}-6$ wo an ester bond. ${ }^{16}$ However. the ${ }^{1} \mathrm{H}^{1.3}{ }^{13} \mathrm{C}$ correlation of the protons is not delected in the HSQC spectrum (Figure 2a) because there is a relatively low concentration of acety lated glucans. compared to unsubstiluted linear periplasmic glucans (Figure la). In another enlarged specirum (Figure 2c). the correlation at $2.18 \mathrm{ppm}$ for ${ }^{1} \mathrm{H}$ and al $21.0 \mathrm{ppm}$ for ${ }^{13} \mathrm{C}$ is identified duc 10 methyl group of substituted acetyl residue. Other signals from $\mathrm{H}-\mathrm{i}$ to $\mathrm{H}-6$ in the proton peak area are designated as shown in Figure $2 \mathrm{a}$.

In this study through matrix-assisted laser desorption/ ionization Time of flight (MALDl-TOF) mass spectrometric and ID or 2D NMR spectroscopic analy sis. we have described that $P$. syringae produces one or wo acetylated linear periplasmic glucans in HO media. which are different from LO media. This fact offers evidence that the substituent structure of periplasmic glucans can be derivalised according to cultural conditions. The produced amount of periplasmic glucans also decreased and instead trehalose as another osmorcgulator responsible for high-osmotic adaptation was newly stythesized (data not shown). This structural analysis of the clanged periplasmic glucans shows the possibility for biological and biotechnological functions of the acetylated linear periplasmic glucans. Some enzsmes that transfer substituents (phosphoglycerol or succinate) to backbone glucan have been reporicd. ${ }^{j-18}$ but there is no study on enrs me for acetylation to periplasmic glucans. In $K$. coth $m d o B$ and $m(t)$ ' encode a membrane bound proteins which transfer phosphogly cerol and succinyl residues. repectively. ${ }^{1.1^{-} .18}$ Gene for transferring acetyl residues has not demonstrated only: acely 1 co A suspects to be the donor moleculc. Thus, the exact mechanism for substituting the acetyl 

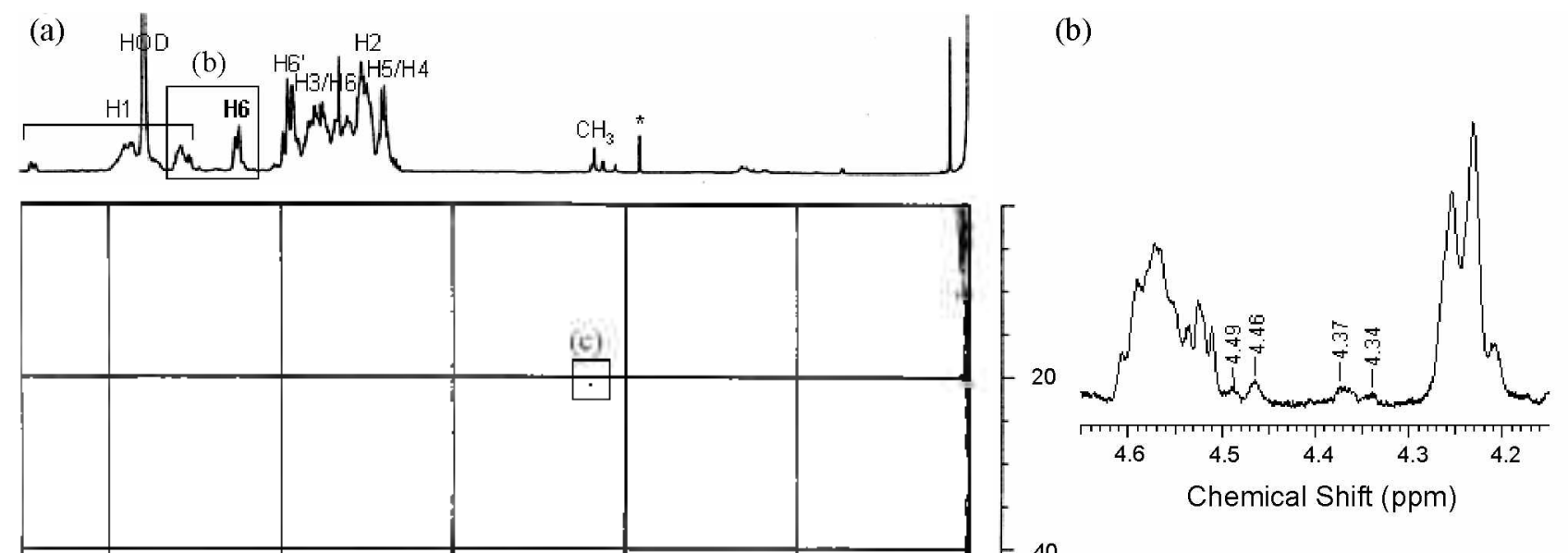

(c)
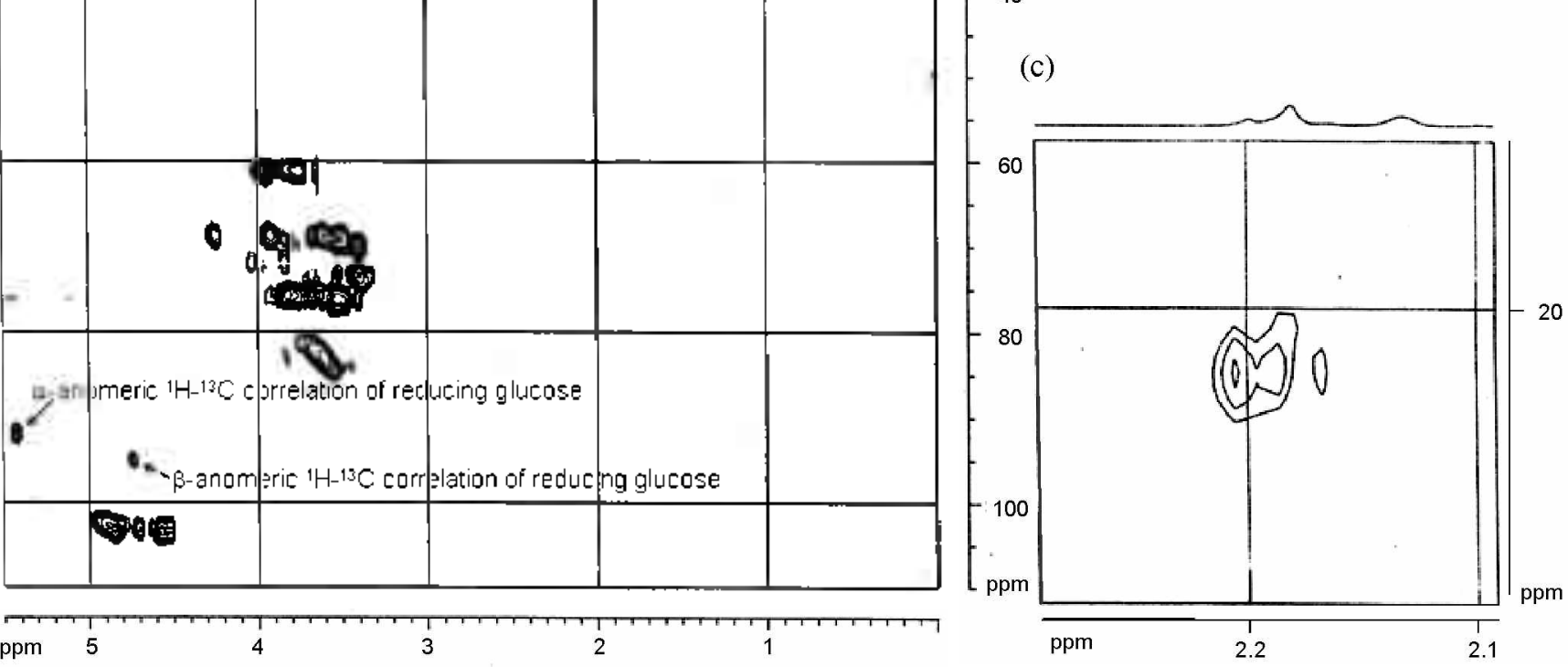

Figure 2. ${ }^{1} \mathrm{H}-{ }^{12} \mathrm{C}$ HSQC spectra (a) of purified neutral linear glucans isolated from $P$. suringae. Protons by the presence of $\beta-1,6$ linked and $\beta-1,2$ linked glucoses, respectively, are designated in bold and ordinary type. HOD means partially deuterated water. * : inpurity by the methyl group of tree acetate. Partial H-NMR spectrum (b) ranges from 4.2 to 4.6 ppm and an expanded HSQC spectrum (c) for the correlation at 2.18 ppm for ${ }^{1} \mathrm{H}$ and at $21.0 \mathrm{ppm}$ for ${ }^{13} \mathrm{C}$ is shown.

group to periplasmic glucans does not exist. Further investigation for this acetylation mechanism is in progress.

\section{Experimental Sections}

Purification of linearglucans. $P$. swingae pv. Syringae (ATCC 19310) was grown on a rotary shaker at $26^{\circ} \mathrm{C}$ in $\mathrm{HO}$ medium. To obtain $\mathrm{HO}$ medium, $0.3 \mathrm{M} \mathrm{NaCl}$ was added to the $\mathrm{LO}$ medium. The microorganisms were collected after $\mathrm{I}$ day by centrifugation at $8,000 \mathrm{mpm}$ for 10 minute. The cell pellets were extracted with $5 \%$ trichloroacetic acid. and the extract was neutralized with ammonia water. The neutralized one was concentrated and applied to a Sephadex G-25 column. The fractions of the putative glucans detected by thin-layer chromatography (TLC) were pooled and concentrated by rotary evaporation. The sample was applied to a DEAE-Sephadex column $(2.5 \times 17.5 \mathrm{~cm})$ to separate the neutral and anionic glucans. which were respectively collected and desalted on a Sephadex G-10 column. The desalted molecule that dissolved in water was finally lyophilized and analyzed.

TLC. The analytes were spotted on the silica Gel G-60 (E. Merck, $400-240$ mesh) TLC plates. The plates were developed under the solvent (butanol : ethanol : water $=5: 5: 4$ ) and dried on the hot plate that measured $120^{\circ} \mathrm{C}^{18}$

MALDI-TOF MS. For MALDI-TOF MS, the glucans were dissolved in water and mixed with the matrix (2.5-dihydroxybenzoic acid). Mass spectra were recorded on a mass spectrometer (Voyager-DE ${ }^{\mathrm{TM}}$ STR BioSpectrometry. PerSeptive Biosystems, Franingham, MA, USA) in positive-ion mode.

NMR spectroscopy. For NMR spectroscopic analyses, the glucans were dissolved in $\mathrm{D}_{2} \mathrm{O}$ at room temperature $\mathrm{A}$ Bruker Avance 500 spectrometer was used to record the ${ }^{l} \mathrm{H}-\mathrm{NMR}$ and HSQC spectra. The HSQC spectrum was recorded using $256 / 2048$ complex data points and $29898 / 484+\mathrm{Hz}$ spectral widths in $\mathrm{tl}$ and $\mathrm{t} 2$. respectively.

Acknowledgments. This research was supported by KOSEF (2009-0059986) in 2008. SDG. 


\section{References}

1. Bohin, T.-P. FEMS 1ficrobiol Lett. 2000, IS6, 11.

2. Mukhopadhyay, P.; Williams, J.; Mills, D. J. Bacteriol. 1988, 170,5479

3. Page, F.: Altabe, S.: Hugouvieux-cotte-pattat, N.; Lacroix, J.-M.; Robert-baudouy, T. Bohin, T.-P. J. Bacteriol. 2001, 183, 3134.

4. Kwon, C.: Paik, S.; Jung, S. Electrophoresis 2008, 29, 4284.

5. Kim, H.; Kim, H.-W., Jung, S. Bull Korean Chem. Soc. 2008, 29,590

6. Park, H.; Kang, L.; Jung, S. Bull. Korean Chem. Soc. 2008, 29 , 228 .

7. Szejtli, T. Chem. Rev. 1998, $98,1743$.

8. Morris, V. I; Brownsey, G. J.: Chilvers, G. R.: Harris, J. E.: Gunning, A. P.; Stevens, B. H. J. Food Hydrocolloids 1991, 5, 185

9. Talaga, P.; Fournet, B.; Bohin, T.-P. J. Bacteriol 1994, 176 , 6538 .
10. Kennedy, E. P. Proc. Natl .1cad. Sci. LS. 1982, 79, 1092.

11. Cogez, V.; Talaga, P.; Lemoine, J.; Bohin, T.-P. J. Bacteriol. $2001,183,3127$.

12. Lequette, Y.; Rollet, E.: Delangle, A.; Greenterg, E. P.: Bohin, T.-P. Aficrobiolog, 2007, 153, 3255 .

13. Van Golde, L. M. G.: Schulman, H.: Kennedy, E. P. Proc. Narl. Acad. Sci. LS.4 1973,70, 1368.

14. Cho, E.; Jeon, Y.; Jung, S. Carbohylr: Res. 2009, 34t, 996.

15. Gidley, M. J. Cartohydr: Res. $1985,139,85$.

16. Matulová, M.: Toffanin, R.; Navarini, L.: Gilli, R.; Paoletti, S.; Cesàro, A. Carbohtr Res. 1994, $265,167$.

17. Jackson, B. J.; Kennedy, E. P. J. Biol. Chem. 1983, $258,2394$.

18. Lacroix, J. M.; Lanfroy, E; Cogez, V.; Lequette, Y.; Bohir1, A.; Bohin, J.-P. J. Bacteriol. $1999,181,3626$.

19. Reinhold, B. B.; Chan, S. Y.; Reuber, T. L.; Marra, A.: Walker, G. C.; Reinhold, V. V.J. Bacteriol 1994, 176, 1997.

20. Lee, S.; Kwon, S.; Kwon, C.: Jung, S. Canbolndr. Res. 2009. $3+4,1127$. 